\title{
Pulmonary Hypertension
}

\author{
Ilknur Basyigit, ${ }^{1}$ Gulfer Okumus, ${ }^{2}$ Serpil Erzurum, ${ }^{3}$ \\ Kewal Asosingh, ${ }^{3}$ and Despina Papakosta ${ }^{4}$ \\ ${ }^{1}$ Department of Pulmonary Disease, Faculty of Medicine, Kocaeli University, 41400 Kocaeli, Turkey \\ ${ }^{2}$ Department of Pulmonary Disease, Faculty of Medicine, Istanbul University, 34452 Istanbul, Turkey \\ ${ }^{3}$ Department of Pathobiology, Lerner Research Institute (NC22), The Cleveland Clinic, \\ 9500 Euclid Avenue, Cleveland, OH 44195, USA \\ ${ }^{4}$ Pulmonary Department, Aristotle University of Thessaloniki, G. Papanicolaou Hospital, Exochi, 57010 Thessaloniki, Greece
}

Correspondence should be addressed to Ilknur Basyigit, ilknur.basyigit@gmail.com

Received 15 October 2012; Accepted 15 October 2012

Copyright (C) 2012 Ilknur Basyigit et al. This is an open access article distributed under the Creative Commons Attribution License, which permits unrestricted use, distribution, and reproduction in any medium, provided the original work is properly cited.

Pulmonary hypertension is a hemodynamic and pathophysiological condition which is defined by right heart catheterization as an increase in mean pulmonary artery pressure above $25 \mathrm{mmHg}$ at rest [1]. Several clinical conditions can result in increased pulmonary arterial pressure, therefore detailed evaluation and accurate diagnosis of the underlying disease is crucial for appropriate treatment [2]. The clinical classification of pulmonary hypertension $(\mathrm{PH})$ advanced since its first version proposed by World Health Organization in 1973. The final version of the clinical classification was derived from the Dana Point Meeting in 2008 (Table 1). Pulmonary hypertension due to left heart disease (clinical group 2) is defined as postcapillary (pulmonary capillary wedge pressure $\geq 15 \mathrm{mmHg}$ ) while precapillary (pulmonary capillary wedge pressure $\leq 15 \mathrm{mmHg}$ ) pulmonary hypertension presents in other groups.

Echocardiography is a widely used screening method in patients with suspected pulmonary hypertension. However, right heart catheterization is required to confirm diagnosis of $\mathrm{PH}$ [2]. The evaluation of the patients should also include clarifying specific etiologies and assessment of the degree of functional and hemodynamic impairment. The majority of pulmonary hypertension cases are due to left heart disease and/or lung disease (clinical groups 2 and 3); idiopathic pulmonary arterial hypertension (PAH) remains a diagnosis of exclusion. Hence, diagnostic algorithms are suggested by several guidelines in order to prevent excessive diagnostic testing for a common disease or under-diagnosis of rare conditions $[1,3]$.
Pulmonary hypertension is common and difficult to manage in critical care units (ICU). In the present issue two specific patient populations admitted to ICU are described: pregnant women and newborns. The physiologic changes developing during pregnancy and after labor are poorly tolerated by the pregnant women. Also acute conditions associated with pregnancy such as pulmonary and amniotic fluid embolism may be complicated with severe pulmonary hypertension [4]. No standardized treatment strategies exist for the management of $\mathrm{PH}$ in pregnancy, and maternal mortality remains high despite lower death rates in the last decade compared with previous era.

$\mathrm{PH}$ occurring in the newborn may result from a variety of causes, most commonly; it presents immediately after birth and is referred to as persistent pulmonary hypertension of the newborn (PPHN), when pulmonary vascular resistance fails to decrease at birth. The majority of cases are associated with lung parenchymal diseases, such as meconium aspiration syndrome, and respiratory distress syndrome. The improvement in the prognosis and the survival in PPHN over the last decade is attributed to early admission to a tertiary centre, the use of new techniques of mechanical ventilation, extracorporeal membrane oxygenation, and the use of new pulmonary vasodilators [5].

Over the last decade, research in pulmonary vascular disease has revealed genetic mutations in heritable $\mathrm{PAH}$, new methods and imaging techniques for diagnosis of $\mathrm{PH}$, methods to assess right ventricular function and remodeling, and clinical impact of the disease and its prognosis in special conditions such as the pediatric population [6]. 
TABLE 1: The clinical classification of pulmonary hypertension [1].

Pulmonary arterial hypertension (PAH)

(i) Idiopathic (IPAH)

(ii) Heritable (HPAH)

(a) Bone morphogenetic protein receptor type 2 (BMPR2)

(b) Activin receptor-like kinase 1 gene (ALK1), endoglin (with or without hereditary hemorrhagic telangiectasia)

(c) Unknown

Group 1

(iii) Drug and toxin induced

(iv) Associated with (APAH)

(a) Connective tissue diseases

(b) Human immunodeficiency virus (HIV) infection

(c) Portal hypertension

(d) Congenital heart disease ( $\mathrm{CHD}$ )

(e) Schistosomiasis

(f) Chronic haemolytic anaemia

(v) Persistent pulmonary hypertension of the newborn (PPHN)

Group 1' Pulmonary veno-occlusive disease (PVOD) and/or pulmonary capillary haemangiomatosis (PCH)

Pulmonary hypertension due to left heart diseases

Group 2 (i) Systolic dysfunction

(ii) Diastolic dysfunction

(iii) Valvular disease

Pulmonary hypertension due to lung diseases and/or hypoxemia

(i) Chronic obstructive pulmonary disease (COPD)

(ii) Interstitial lung disease (ILD)

Group 3 (iii) Other pulmonary diseases with mixed restrictive and obstructive pattern

(iv) Sleep-disordered breathing

(v) Alveolar hypoventilation disorders

(vi) Chronic exposure to high altitude

(vii) Developmental abnormalities

Group 4 Chronic thromboembolic pulmonary hypertension (CTEPH)

$\mathrm{PH}$ with unclear and/or multifactorial mechanisms

(i) Haematological disorders: myeloproliferative disorders, splenectomy

Group 5 (ii) Systemic disorders: sarcoidosis, pulmonary Langerhans cell histiocytosis, lymphangioleiomyomatosis, neurofibromatosis, and vasculitis

(iii) Metabolic disorders: glycogen storage disease, Gaucher disease, and thyroid disorders

(iv) Others: tumoral obstruction, fibrosing mediastinitis, and chronic renal failure on dialysis

This special issue aims to identify current limitations as well as future goals to advance the approach to patients with pulmonary vascular disease. The readers will find concise reviews about pulmonary hypertension in newborns and pregnant women, under recognized etiologies of $\mathrm{PH}$ and functional impairment of the disease.

\section{References}

[1] Task Force for Diagnosis and Treatment of Pulmonary Hypertension of European Society of Cardiology (ESC), European Respiratory Society (ERS), International Society of Heart and Lung Transplantation (ISHLT) et al. et al., "Guidelines for the diagnosis and treatment of pulmonary hypertension," European Respiratory Journal, vol. 34, no. 6, pp. 1219-1263, 2009.

[2] S. J. Shah, "Pulmonary hypertension," Journal of the American Medical Association, vol. 308, no. 13, pp. 1366-1374, 2012.

[3] V. V. McLaughlin, S. L. Archer, D. B. Badesch et al., "ACCF/AHA 2009 expert consensus document on pulmonary hypertension. A report of the American College of Cardiology Foundation Task Force on Expert Consensus Documents and the American Heart Association Developed in Collaboration With the American College of Chest Physicians; American Thoracic Society, Inc.; and the Pulmonary Hypertension Association," Journal of 
the American College of Cardiology, vol. 53, no. 17, pp. 15731619, 2009.

[4] S. E. Stone and T. A. Morris, "Pulmonary embolism during and after pregnancy," Critical Care Medicine, vol. 33, no. 10, pp. S294-S300, 2005.

[5] G. G. Konduri and U. O. Kim, "Advances in the diagnosis and management of persistent pulmonary hypertension of the newborn," Pediatric Clinics of North America, vol. 56, no. 3, pp. 579-600, 2009.

[6] P. M. Hassoun and S. Adnot, "Update in pulmonary vascular disease 2011," American Journal of Respiratory and Critical Care Medicine, vol. 185, no. 11, pp. 1177-1182, 2012. 


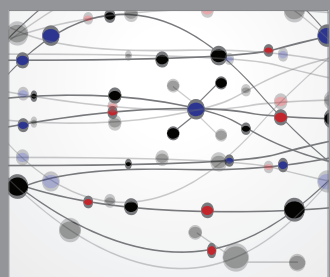

The Scientific World Journal
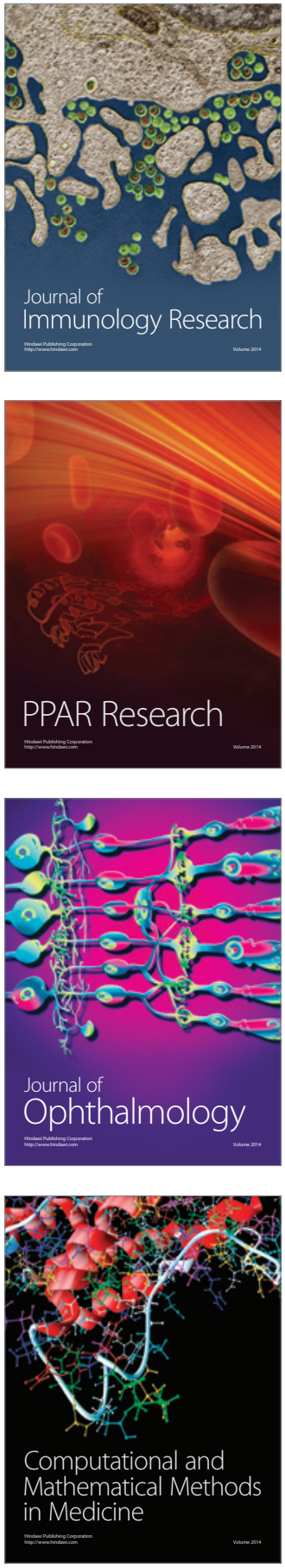

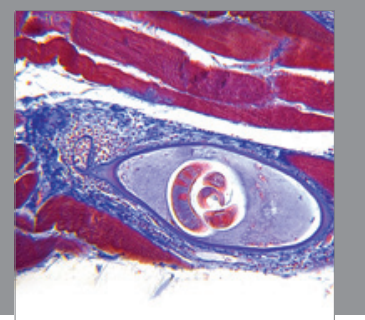

Gastroenterology

Research and Practice
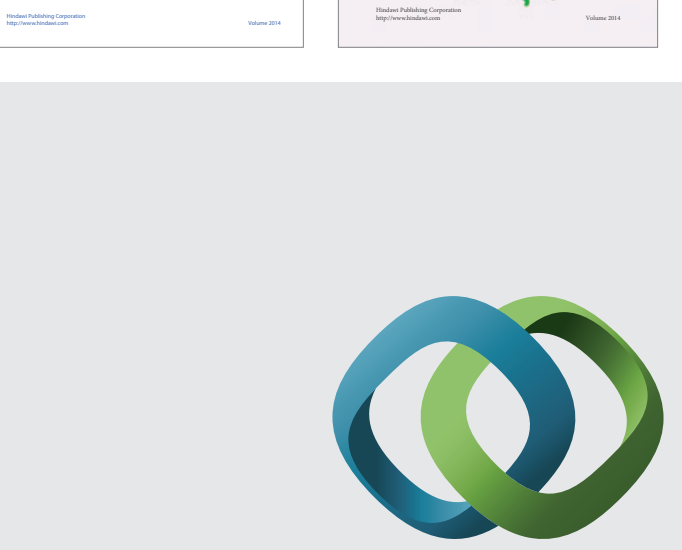

\section{Hindawi}

Submit your manuscripts at

http://www.hindawi.com
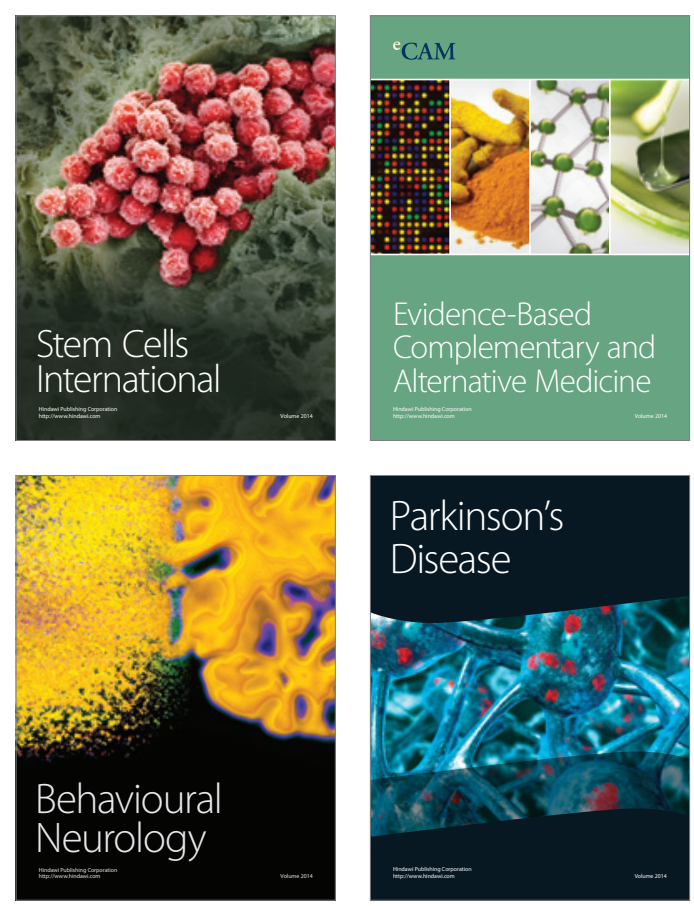

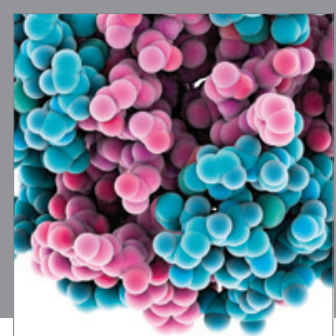

Journal of
Diabetes Research

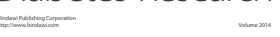

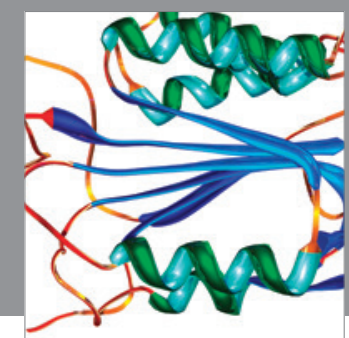

Disease Markers
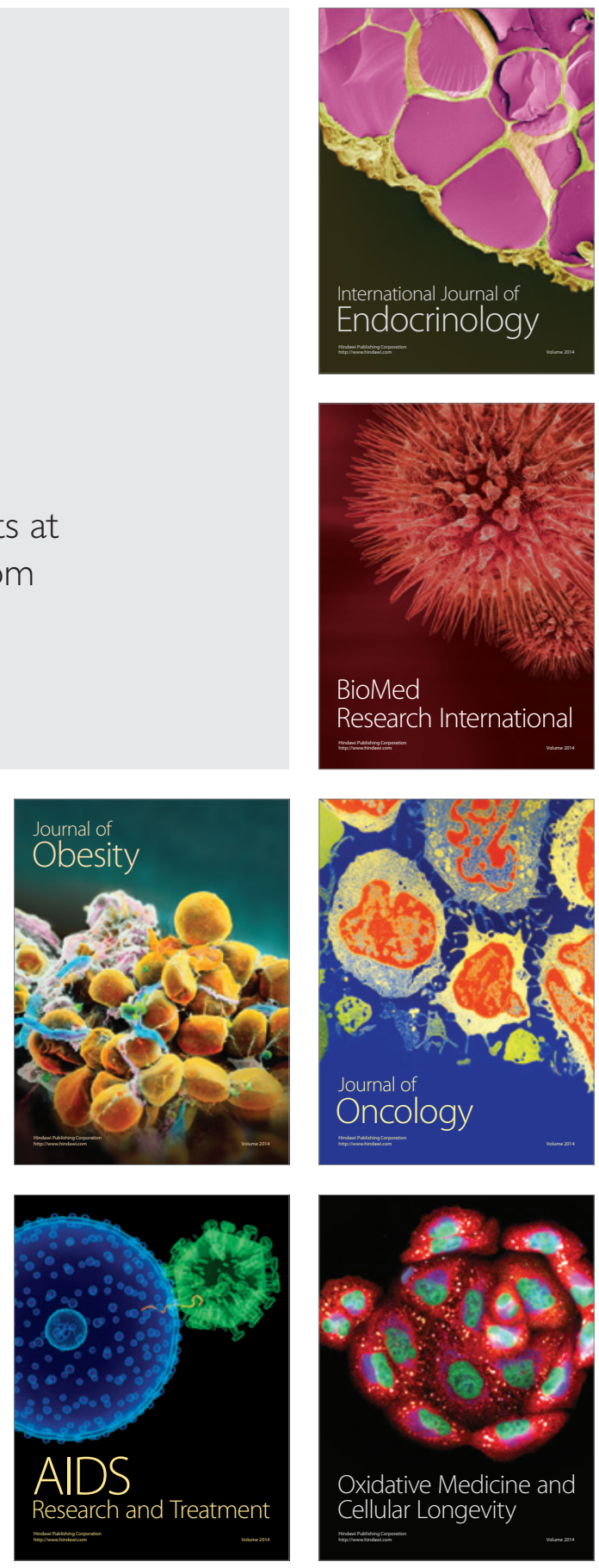